\title{
Economic and caregiver impact of Alzheimer's disease across the disease spectrum: a cohort study
}

Virginie Dauphinot ${ }^{1,2^{*}} \mathbb{0}$, Michele Potashman ${ }^{3}$, Mihaela Levitchi-Benea ${ }^{3}$, Ray Su ${ }^{3}$, Ivana Rubino ${ }^{3}$ and

Pierre Krolak-Salmon ${ }^{1,2,4}$

\begin{abstract}
Background: Alzheimer's disease (AD) substantially increases health-related costs. This study investigates direct medical costs and characterizes the caregiver burden across AD stages.

Methods: This study analyzed data from the French Primary Health Insurance Fund claims database and reflected this public payer perspective. Outpatients $(N=1998)$ visiting a memory clinic at Lyon University Hospital in France between 2014 and 2019 were included. Real healthcare costs (ie, ambulatory medicine, paramedical care, pharmaceutical treatment, public and private hospital stays, and medical transportation) were collected for patients 1 year prior to the date of the first memory visit and 2 years following the first visit (reference year: 2019). Patients were grouped based on a clinical diagnosis of cognitively normal with a subjective cognitive complaint (SCC), all-cause mild cognitive impairment $(\mathrm{MCl})$, or $\mathrm{AD}$ dementia. The severity of $\mathrm{AD}$ dementia was defined by the Mini-Mental State Examination score. Caregiver burden was measured using the mini Zarit Burden Interview. A generalized linear model was used for statistical analyses. Other patient nonmedical and indirect costs and caregiver costs were not included.

Results: The study sample included patients with SCC $(n=640), \mathrm{MCI}(n=630)$, mild $(n=212)$, moderate $(n=256)$, or moderately severe/severe AD dementia $(n=260)$. One year after the first consultation, mean total costs were higher with progressive cognitive deficit, with little difference between dementia groups (SCC = $€ 8028 ; \mathrm{MCl}=€ 9758$; mild $A D$ dementia $=€ 10,558$; moderate $A D$ dementia $=€ 10,544$; moderately severe/severe $A D$ dementia $=€ 10,345$; $P<.001)$. Public hospital stays comprised the majority of direct medical costs during the first semester following the visit (49.4\% of the total costs), regardless of the severity of cognitive deficit. Caregiver burden increased with the severity of cognitive deficit $(P<.0001)$.

Conclusions: Direct medical costs and caregiver burden rose from SCC to AD dementia; in patients with AD dementia, the direct medical costs increased over the 2 years after the first consultation. These results, in conjunction with data from other care components, will be critical to elucidate the potential economic value of a therapeutic intervention that slows AD progression.
\end{abstract}

Keywords: Costs of care, Economics, Alzheimer's disease, Ccognitive status

*Correspondence: virginie.dauphinot@chu-lyon.fr

${ }^{1}$ Clinical and Research Memory Centre of Lyon, Lyon Institute For Elderly, Lyon University Hospital, Lyon, France

Full list of author information is available at the end of the article

\section{Background}

Alzheimer's disease (AD) substantially increases healthrelated costs in developed countries [1]. In 2015, dementia incurred a societal cost of $€ 730$ billion in the USA, rising from an estimated $€ 452$ billion in 2010. In Europe, original author(s) and the source, provide a link to the Creative Commons licence, and indicate if changes were made. The images or other third party material in this article are included in the article's Creative Commons licence, unless indicated otherwise in a credit line to the material. If material is not included in the article's Creative Commons licence and your intended use is not permitted by statutory regulation or exceeds the permitted use, you will need to obtain permission directly from the copyright holder. To view a copy of this licence, visit http://creativecommons.org/licenses/by/4.0/. The Creative Commons Public Domain Dedication waiver (http://creativeco mmons.org/publicdomain/zero/1.0/) applies to the data made available in this article, unless otherwise stated in a credit line to the data. 
the estimated cost of dementia was $€ 105.2$ billion in 2010 [2]. AD encompasses a continuum ranging from cognitively normal individuals with biomarker evidence of $\mathrm{AD}$ to individuals with severe AD dementia [3]. It is critical to evaluate the costs of resources used at every stage of the disease to more accurately estimate how future interventions will affect the economic costs of $A D$. While the immense socioeconomic burden of $\mathrm{AD}$ has been described, costs and burden related to specific stages along the $\mathrm{AD}$ continuum are not well characterized. For instance, most studies have estimated the average cost per patient without taking into account predementia stages [4-10]. Additionally, these costs were often presented with different amplitudes depending on population characteristics, study perspectives (payer or societal), cost components (direct, indirect, or informal), and time of evaluation, making comparisons difficult across studies [4-10]. Health expenditures associated with patient care are also limited, despite being an objective evaluation of costs related to patient care [10].

Here, we investigated medical and nonmedical direct costs, obtained from the local branch of the French Primary Health Insurance Fund (PHIF) in patients with a clinical diagnosis of cognitively normal with a subjective cognitive complaint (SCC), all-cause mild cognitive impairment (MCI), or mild, moderate, or moderately severe/severe AD dementia. We also investigate the caregiver burden associated with $\mathrm{AD}$ progression.

\section{Methods}

\section{Study design and setting}

This is an ancillary study from the MEMORA cohort, which aimed to investigate the determinants associated with functional change in individuals receiving routine care [11]. In the present study, the patients' clinical data were matched 1 year before and 2 years after the first memory consultation with claims data from the local branch of the PHIF (Caisse Primaire d'Assurance Maladie du Rhône [CPAM]) database for patients from the MEMORA cohort who underwent a consultation at a memory clinic of the Lyon University Hospital in France between 2014 and 2019. This claims database included all the direct medical costs taken in charge by the national healthcare system, as well as medical transportation [12]. All patients had cognitive complaints, which were expressed by the patient or caregiver. Data matching led to a database including 4173 patients, which represented $61.2 \%$ of the initial MEMORA cohort in this period. The absence of data matching was due to wrong coding, misspelled names between the 2 databases, or because the patient depended on insurance other than the French PHIF, or, more specifically, the Rhône Primary Health Insurance Fund.

\section{Study population}

Patients met the following inclusion criteria: living at home or in community-based housing, having coverage by the PHIF, having $\geq 1$ year of follow-up, and having a clinical diagnosis at the first visit by SCC and a MiniMental State Examination (MMSE) score $>26$, all-cause $\mathrm{MCI}$ and an MMSE score $<26$, or AD dementia at mild, moderate, or moderately severe/severe stages defined by an MMSE score of 20 to 26,15 to 19 , or < 14, respectively. Exclusion criteria included patients under legal protection. Information regarding the collection of individual data, with the aim of performing research on routine care, was provided to the patients. This ancillary research of the MEMORA study was considered noninterventional by the local ethics committee CPP Lyon Sud-Est IV (Comite de Protection des Personnes [Committee for the Protection of People]). No signed consent was required for participation, but patients may refuse the use of their data for research purposes. Authorization for handling personal data was granted by the representative of the French Data Protection Authority, the Commission Nationale de l'Informatique et Libertés. All procedures are in compliance with the Declaration of Helsinki. The MEMORA cohort also obtained agreements from the regional ethics committee, Comité de Protection des Personnes Sud Est III and the French Data Protection Authority (ClinicalTrials.gov code: NCT02302482).

\section{Primary outcome}

Primary outcomes included source of healthcare costs, components of claims data, valorization of the costs, and caregiver impact. First, healthcare costs, reflecting a healthcare payer perspective, were assessed for each care, act, and treatment that occurred for the insurance recipient and was reimbursed through the local branch of the PHIF. Claims data included all medical direct costs and the one nonmedical direct cost, medical transportation, which was supported by the local PHIF; PHIF is the equivalent of the national claims database described elsewhere [13].

Second, components of claim data included (1) ambulatory medicine (e.g., consultations and care provided by general practitioners, neurologists, psychiatrists, and geriatricians) and other ambulatory care (e.g., surgical procedures in private practice, ophthalmologic and hearing devices, dental care, biological analyses, radiology examinations, immunization, home dialysis, at-home hospitalizations, and health cures); (2) paramedical care from nurses, physiotherapists, and others, such as speech therapists or orthoptists; (3) pharmaceutical treatment from retail pharmacies for AD medication, psychotics/ hypnotics, and other pharmaceutical treatment using the 
Anatomical Therapeutic Chemical classification of the World Health Organization; (4) costs related to hospital stays in geriatric wards, psychiatric wards, internal medicine wards, and surgery wards and all other costs related to hospital stays; and (5) private hospital stays. Medical transportation is the only nonmedical direct cost covered by the PHIF that was considered in this study.

Third, valorization of costs was presented as constant costs adjusted for the value of the euro in 2019 according to Institut Nationale de la Statistique et des Etudes Economiques (French national institute for statistical and economic studies; https://www.insee.fr/fr/information/ 2417794). Costs per patient were expressed as the sum of the costs per semester and per year (for the total costs), both overall and according to the item of interest, within the time frame of 1 year prior to the date of the first memory visit and 2 years following the first visit. Total costs for patients who died were considered in the corresponding semester. Costs related to a nursing home were not included for all groups. Notably, the PHIF applies a specific reimbursement level, which is similar nationally, for each care, act, and treatment. However, reimbursement rates may vary according to several criteria; details are publicly available at https://www.service-public.fr/ particuliers/vosdroits/N418. The prices and rates taken in charge by the PHIF are listed in Supplementary Table 1. The average costs paid by the patient and the estimated costs reimbursed by the PHIF are also presented.

Fourth, caregiver burden was assessed using the short version of the Zarit Burden Interview (sZBI) during a face-to-face interview between the caregiver and nurses during the memory consultation [14]. A higher sZBI score indicates a higher burden (range of 0 to 7 ).

\section{Collection of data}

Baseline characteristics were collected at the initial visit. Clinical data were collected at the memory consultation by trained nurses and administrative staff and recorded in an electronic case report form. Cognitive performance was assessed using the MMSE. The total score ranges from 0 to 30, and a lower score indicates increased cognitive impairment [15]. Functional abilities were evaluated using the Lawton Instrumental Abilities of Daily Living (IADL) scale; the summary score ranges from 0 to 8 , with 8 indicating autonomy [16]. The behavioral and psychological symptoms of dementia were assessed using the Neuropsychiatric Inventory (NPI); the total NPI score ranges from 0 to 144 , and 144 indicates a severe behavioral disorder [17]. Clinical diagnosis was determined by a neurologist, geriatrician, or psychiatrist based on clinical assessments and by using the MMSE score. Patients were diagnosed with SCC when they performed normally on the neuropsychological assessment but the patient expressed a cognitive complaint or the caregiver reported one for the patient; in addition, patients had to have an MMSE score $\geq 26$ at the time of diagnosis. A diagnosis of MCI or AD dementia was established using the 2011 National Institute on Aging-Alzheimer's Association criteria and the Diagnostic and Statistical Manual of Mental Disorders, Fifth Edition [18-20]. In addition, patients with MCI or AD dementia had to have an MMSE score $<26$ at the time of diagnosis. Dementia severity was assessed using the MMSE score: 20 to 26 for mild AD dementia, 15 to 19 for moderate AD dementia, and $\leq$ 14 for moderately severe/severe AD dementia. These thresholds were similar to those used in previous studies $[21,22]$.

The dates of nursing home admission and death and the treatments for comorbidities (e.g., arterial hypertension, diabetes mellitus, hypercholesterolemia, depression, and anxiety) were collected from the PHIF database. During the study, a patient was considered to have a comorbidity if they received reimbursement of treatment for one.

\section{Statistical analysis}

Patient demographics were presented as mean \pm standard deviation (SD) or frequency (percentage). Betweengroup comparisons were performed using analysis of variance or Pearson chi-squared test. Paired-wise comparisons were made using post hoc Bonferroni and Sheffé tests. The occurrence of nursing home admission and death was described according to the semester and during the study period (2014-2019).

Costs per patient were described in euros per semester and per year and according to the diagnosis. Total costs were classified as medical or nonmedical and categorized according to the different origins of the costs, using means (SD, SE, or 95\% CI) and medians (IQR). Total costs were also described by age $(\geq 80$ years vs. $<$ 80 years), gender, educational level ( $\geq 12$ years vs. $<12$ years), and treatment for comorbidities.

Total costs were compared between groups by semester using generalized linear models (GLM) with gamma distribution and log link [23]. As the nonmedical direct costs of medical transportation did not represent a large amount, these costs were added to the medical direct costs to calculate a total cost per patient. The sZBI scores were compared between groups using GLM. P values unadjusted and adjusted for age, gender, and education level were reported. Analyses were performed using Statistical Package for the Social Sciences (SPSS) version 19.0 for Windows (SPSS Inc., Chicago, Illinois, USA).

\section{Sensitivity analyses}

Due to large differences between mean and median costs, patients with costs $\geq 3$ SDs from the mean were 
identified as outliers. Outlier patient characteristics and resource utilization, as well as the implications of removing outliers from analyses, were assessed. A Student $t$-test or the Pearson chi-squared test was used to assess patient characteristics with 3 SDs above or below average total costs. The association between diagnosis and total costs was tested when excluding outliers using GLM with log link and gamma distribution.

\section{Results}

\section{Patient demographics}

In patients $(N=1998)$ included in the study, 640 were cognitively normal with SCC; 630 patients had MCI of unspecified etiology; and 212, 256, and 260 patients had mild, moderate, or moderately severe/severe AD dementia, respectively (Table 1 , Supplementary Fig. 1). Most patients $(52.9 \%)$ were aged $\geq 80$ years or over, except in the SCC group (33.3\%); 63\% were female. There were fewer patients in the moderate and severe AD dementia groups with an education level $>12$ years compared with other groups $(P<.001)$. The mean MMSE decreased significantly with the severity of cognitive deficit $(P<.001)$. Similarly, the IADL score decreased with cognitive deficit severity $(P<.001)$. However, no significant difference in IADL scores occurred between the mild AD dementia (mean IADL $=4 \pm 2$ ) and moderate AD dementia groups (mean IADL $=3.6 \pm 2$ ); a post hoc test result was 0.16 . Further, the proportion of patients treated for depression $(P<.001)$ was significantly higher in the AD dementia group compared with other groups.

\section{Costs according to the severity of cognitive deficit}

When comparing the total costs by diagnosis, the mean total costs 1 year after the first consultation tended to increase with the severity of cognitive deficit $(\mathrm{SCC}=$ $€ 8028 ; \mathrm{MCI}=€ 9758$; mild $\mathrm{AD}$ dementia $=€ 10,558$; moderate $\mathrm{AD}$ dementia $=€ 10,544$; moderately severe/ severe $\mathrm{AD}$ dementia $=€ 10,345 ; P<.001)$ (Table 2). The analysis per semester showed similar trends. Mean total costs in the first semester were numerically higher for the $\mathrm{MCI}$ and $\mathrm{AD}$ dementia groups compared with the SCC group $(\mathrm{SCC}=€ 4578 ; \mathrm{MCI}=€ 4876$; mild $\mathrm{AD}$ dementia $=€ 5282$; moderate $\mathrm{AD}$ dementia $=€ 5443$; severe $\mathrm{AD}$ dementia $=€ 4969$; Supplementary Table 2).

\section{Analysis of costs details}

Regardless of the patient diagnosis, costs were highest 1 year after the first visit (Fig. 1; Supplementary Table 2). In the SCC

Table 1 Description of the study population

\begin{tabular}{|c|c|c|c|c|c|c|c|}
\hline & Total & SCC & $\mathrm{MCl}$ & Mild AD dementia & $\begin{array}{l}\text { Moderate AD } \\
\text { dementia }\end{array}$ & $\begin{array}{l}\text { Moderately } \\
\text { severe/severe AD } \\
\text { dementia }\end{array}$ & $P$ value* \\
\hline & $(N=1998)$ & $(n=640)$ & $(n=630)$ & $(n=212)$ & $(n=256)$ & $(n=260)$ & \\
\hline Age, mean (SD) & $78.62(8.61)$ & 74.58 (9.98) & $79.02(7.62)$ & $81.69(6.63)$ & $82.37(5.97)$ & $81.41(6.63)$ & $<.001$ \\
\hline \multicolumn{8}{|l|}{ Sex, $n(\%)$} \\
\hline Female & $1259(63.00)$ & $369(57.66)$ & $388(61.59)$ & $131(61.79)$ & $185(72.27)$ & $186(71.54)$ & \multirow[t]{2}{*}{$<.001$} \\
\hline Male & $739(37.00)$ & $271(42.34)$ & $242(38.41)$ & $81(38.21)$ & $71(27.73)$ & $74(28.46)$ & \\
\hline \multicolumn{8}{|l|}{ Education level, $n$ (\%) } \\
\hline$\geq 12$ years & $456(22.4)$ & 319 (49.84) & $152(24.13)$ & $66(31.13)$ & $44(17.19)$ & $29(11.15)$ & \multirow[t]{3}{*}{$<.001$} \\
\hline$<12$ years & $1306(64.1)$ & $280(43.75)$ & 447 (70.95) & $146(68.87)$ & $212(82.81)$ & $230(88.46)$ & \\
\hline Unknown & $276(13.5)$ & $41(6.41)$ & $31(4.92)$ & 0 & 0 & $1(0.38)$ & \\
\hline $\begin{array}{l}\text { MMSE score (out of 30), } \\
\text { mean (SD) }(n=1962)\end{array}$ & $22.08(6.14)$ & $28.02(1.32)$ & $23.28(1.95)$ & $22.36(1.90)$ & $17.12(1.45)$ & $10.07(3.43)$ & $<.001$ \\
\hline $\begin{array}{l}\text { IADL (out of 8), mean } \\
\text { (SD) }\end{array}$ & $5.06(2.40)$ & $6.57(1.79)$ & $5.49(2.09)$ & $4.01(2.04)$ & $3.62(1.97)$ & $2.54(1.83)$ & $<.001$ \\
\hline $\begin{array}{l}\text { NPI (out of 144), mean } \\
\text { (SD) }(n=1396)\end{array}$ & $18.49(16.11)$ & $16.41(15.14)$ & $15.75(15.17)$ & 19.16 (16.69) & $21.01(15.74)$ & $23.25(17.45)$ & $<.001$ \\
\hline \multicolumn{8}{|c|}{ Received treatment for comorbidities, $n$ (\%) } \\
\hline Hypertension & $1294(64.76)$ & $368(57.50)$ & $449(71.27)$ & $147(69.34)$ & $153(59.77)$ & $177(69.08)$ & $<.0001$ \\
\hline Diabetes mellitus & $360(18)$ & $110(17.19)$ & $112(17.78)$ & $49(23.11)$ & $36(14.06)$ & $53(20.38)$ & .10 \\
\hline Hypercholesterolemia & 731 (36.59) & $212(33.12)$ & $273(43.33)$ & $78(36.79)$ & $82(32.03)$ & $86(33.08)$ & $<.0001$ \\
\hline Depression & $902(45.15)$ & $256(40)$ & $270(42.86)$ & $108(50.94)$ & $122(47.66)$ & $146(56.15)$ & $<.0001$ \\
\hline Anxiety & $650(32.53)$ & $188(29.38)$ & $210(33.33)$ & $63(29.72)$ & $85(33.20)$ & $104(40)$ & .033 \\
\hline
\end{tabular}

AD Alzheimer's disease, IADL Lawton Instrumental Abilities of Daily Living, MCI mild cognitive impairment, MMSE Mini-Mental State Examination, NPI Neuropsychiatric Inventory, SCC subjective cognitive complaint, SD standard deviation

*ANOVA or chi ${ }^{2}$ of Pearson test 
Table 2 Costs per year according to the severity of the diagnosis

\begin{tabular}{|c|c|c|c|c|c|}
\hline & & & 1 year before & First year after & Second year after \\
\hline \multirow[t]{17}{*}{ All patients } & $N$ & & 1928 & 1998 & 1600 \\
\hline & Missing, $n$ & & 70 & 0 & 398 \\
\hline & Total costs, $€$ & Mean & 7408 & 9466 & 8870 \\
\hline & & SD & 14,941 & 17,664 & 15,759 \\
\hline & & SE & 340 & 395 & 394 \\
\hline & & Median & 2054 & 3444 & 3249 \\
\hline & & IQR & 2705 & 4780 & 4843 \\
\hline & Direct medical costs, $€$ & Mean & 7101 & 9103 & 8590 \\
\hline & & SD & 14,081 & 17,097 & 15,448 \\
\hline & & SE & 321 & 383 & 386 \\
\hline & & Median & 2014 & 3313 & 3088 \\
\hline & & IQR & 2613 & 4674 & 4662 \\
\hline & Direct nonmedical costs (transportation), $€$ & Mean & 307 & 363 & 280 \\
\hline & & SD & 4132 & 2758 & 2212 \\
\hline & & SE & 180 & 102 & 92 \\
\hline & & Median & 166 & 288 & 262 \\
\hline & & IQR & 254 & 399 & 325 \\
\hline \multirow[t]{17}{*}{ SCC } & n & & 619 & 640 & 513 \\
\hline & Missing, $n$ & & 21 & 0 & 127 \\
\hline & Total costs, $€$ & Mean & 7104 & 8028 & 6196 \\
\hline & & SD & 14,964 & 15,016 & 11,917 \\
\hline & & SE & 601 & 594 & 526 \\
\hline & & Median & 1798 & 2576 & 1811 \\
\hline & & IQR & 2285 & 3289 & 2915 \\
\hline & Direct medical costs, $€$ & Mean & 6604 & 7581 & 5885 \\
\hline & & SD & 13,234 & 14,011 & 11,365 \\
\hline & & SE & 532 & 554 & 502 \\
\hline & & Median & 1764 & 2532 & 1802 \\
\hline & & IQR & 2128 & 3223 & 2747 \\
\hline & Direct nonmedical costs (transportation), $€$ & Mean & 500 & 447 & 310 \\
\hline & & SD & 5941 & 3678 & 3150 \\
\hline & & SE & 480 & 261 & 268 \\
\hline & & Median & 153 & 266 & 233 \\
\hline & & IQR & 227 & 433 & 240 \\
\hline
\end{tabular}


Table 2 (continued)

\begin{tabular}{|c|c|c|c|c|c|}
\hline & & & 1 year before & First year after & Second year after \\
\hline \multirow[t]{17}{*}{$\mathrm{MCl}$} & $n$ & & 610 & 630 & 511 \\
\hline & Missing, $n$ & & 20 & 0 & 119 \\
\hline & \multirow[t]{5}{*}{ Total costs, $€$} & Mean & 7899 & 9758 & 8452 \\
\hline & & SD & 15,626 & 18,297 & 14,291 \\
\hline & & SE & 633 & 729 & 632 \\
\hline & & Median & 2160 & 3486 & 3286 \\
\hline & & $\mathrm{IQR}$ & 2588 & 4672 & 4639 \\
\hline & \multirow[t]{5}{*}{ Direct medical costs, $€$} & Mean & 7596 & 9361 & 8130 \\
\hline & & SD & 14,946 & 17,665 & 13,849 \\
\hline & & SE & 605 & 704 & 613 \\
\hline & & Median & 2130 & 3329 & 3073 \\
\hline & & $\mathrm{IQR}$ & 2563 & 4591 & 4180 \\
\hline & \multirow[t]{5}{*}{ Direct nonmedical costs (transportation), $€$} & Mean & 303 & 397 & 323 \\
\hline & & SD & 4143 & 3088 & 2553 \\
\hline & & SE & 310 & 194 & 183 \\
\hline & & Median & 185 & 357 & 309 \\
\hline & & IQR & 310 & 452 & 447 \\
\hline \multirow[t]{17}{*}{ Mild AD dementia } & $n$ & & 204 & 212 & 173 \\
\hline & Missing, $n$ & & 8 & 0 & 39 \\
\hline & \multirow[t]{5}{*}{ Total costs, $€$} & Mean & 8022 & 10,558 & 13,717 \\
\hline & & SD & 18,658 & 18,583 & 24,093 \\
\hline & & SE & 1306 & 1276 & 1832 \\
\hline & & Median & 2370 & 5136 & 5512 \\
\hline & & IQR & 2861 & 5275 & 4695 \\
\hline & \multirow[t]{5}{*}{ Direct medical costs, $€$} & Mean & 7889 & 10,244 & 13,462 \\
\hline & & SD & 18,426 & 18,317 & 23,946 \\
\hline & & SE & 1290 & 1258 & 1821 \\
\hline & & Median & 2358 & 4765 & 5512 \\
\hline & & IQR & 2867 & 5434 & 4835 \\
\hline & \multirow[t]{5}{*}{ Direct nonmedical costs (transportation), $€$} & Mean & 133 & 314 & 254 \\
\hline & & SD & 755 & 1088 & 909 \\
\hline & & SE & 101 & 115 & 106 \\
\hline & & Median & 187 & 294 & 283 \\
\hline & & IQR & 324 & 462 & 274 \\
\hline
\end{tabular}


Table 2 (continued)

\begin{tabular}{|c|c|c|c|c|c|}
\hline & & & 1 year before & First year after & Second year after \\
\hline \multirow[t]{17}{*}{ Moderate AD dementia } & \multicolumn{2}{|l|}{$n$} & 242 & 256 & 208 \\
\hline & \multicolumn{2}{|l|}{ Missing, $n$} & 14 & 0 & 48 \\
\hline & \multirow[t]{5}{*}{ Total costs, $€$} & Mean & 6081 & 10544 & 9783 \\
\hline & & SD & 10,362 & 18,688 & 14,155 \\
\hline & & SE & 666 & 1168 & 981 \\
\hline & & Median & 2047 & 4384 & 4145 \\
\hline & & IQR & 3682 & 5672 & 6257 \\
\hline & \multirow[t]{5}{*}{ Direct medical costs, $€$} & Mean & 5977 & 10,256 & 9589 \\
\hline & & SD & 10,167 & 18,377 & 13,993 \\
\hline & & SE & 654 & 1149 & 970 \\
\hline & & Median & 2018 & 4292 & 4095 \\
\hline & & IQR & 3682 & 5856 & 6446 \\
\hline & \multirow[t]{5}{*}{ Direct nonmedical costs (transportation), $€$} & Mean & 104 & 288 & 193 \\
\hline & & SD & 811 & 1349 & 847 \\
\hline & & SE & 98 & 140 & 98 \\
\hline & & Median & 102 & 263 & 280 \\
\hline & & IQR & 103 & 325 & 297 \\
\hline \multirow{17}{*}{$\begin{array}{l}\text { Moderately severe/severe } \\
\text { AD dementia }\end{array}$} & \multicolumn{2}{|l|}{$n$} & 253 & 260 & 195 \\
\hline & \multicolumn{2}{|l|}{ Missing, $n$} & 7 & 0 & 65 \\
\hline & \multirow[t]{5}{*}{ Total costs, $€$} & Mean & 7740 & 10,345 & 11,728 \\
\hline & & SD & 13,483 & 20,077 & 18,903 \\
\hline & & SE & 848 & 1245 & 1354 \\
\hline & & Median & 2212 & 4130 & 4993 \\
\hline & & IQR & 4613 & 6323 & 8169 \\
\hline & \multirow[t]{5}{*}{ Direct medical costs, $€$} & Mean & 7563 & 10,161 & 11,525 \\
\hline & & SD & 13,090 & 19,914 & 18,810 \\
\hline & & SE & 823 & 1235 & 1347 \\
\hline & & Median & 2207 & 4125 & 4448 \\
\hline & & IQR & 4603 & 6222 & 7857 \\
\hline & \multirow[t]{5}{*}{ Direct nonmedical costs (transportation), $€$} & Mean & 178 & 184 & 203 \\
\hline & & SD & 1975 & 1042 & 615 \\
\hline & & SE & 238 & 109 & 64 \\
\hline & & Median & 212 & 229 & 213 \\
\hline & & IQR & 230 & 236 & 217 \\
\hline \multicolumn{3}{|l|}{$P$ value* } & 0.096 & 0.004 & $<.0001$ \\
\hline \multicolumn{3}{|l|}{$P$ value $^{\dagger}$} & 0.487 & 0.225 & $<.0001$ \\
\hline
\end{tabular}

$A D$ Alzheimer's disease, GLM generalized linear model, IQR interquartile range, $M C /$ mild cognitive impairment, SCC subjective cognitive complaint, $S D$ standard deviation, $S E$ standard error

*GLM to compare mean total costs between the different diagnoses

${ }^{\dagger}$ GLM adjusted for age, sex, and education level

and MCI groups, mean annual total costs increased in the first year after diagnosis but decreased in the second year; costs also decreased in the moderate $\mathrm{AD}$ dementia group, but the decrease was more slight (Table 2). For mild $\mathrm{AD}$ and moderately severe/severe AD dementia groups, mean annual total costs increased for 2 years after diagnosis. 


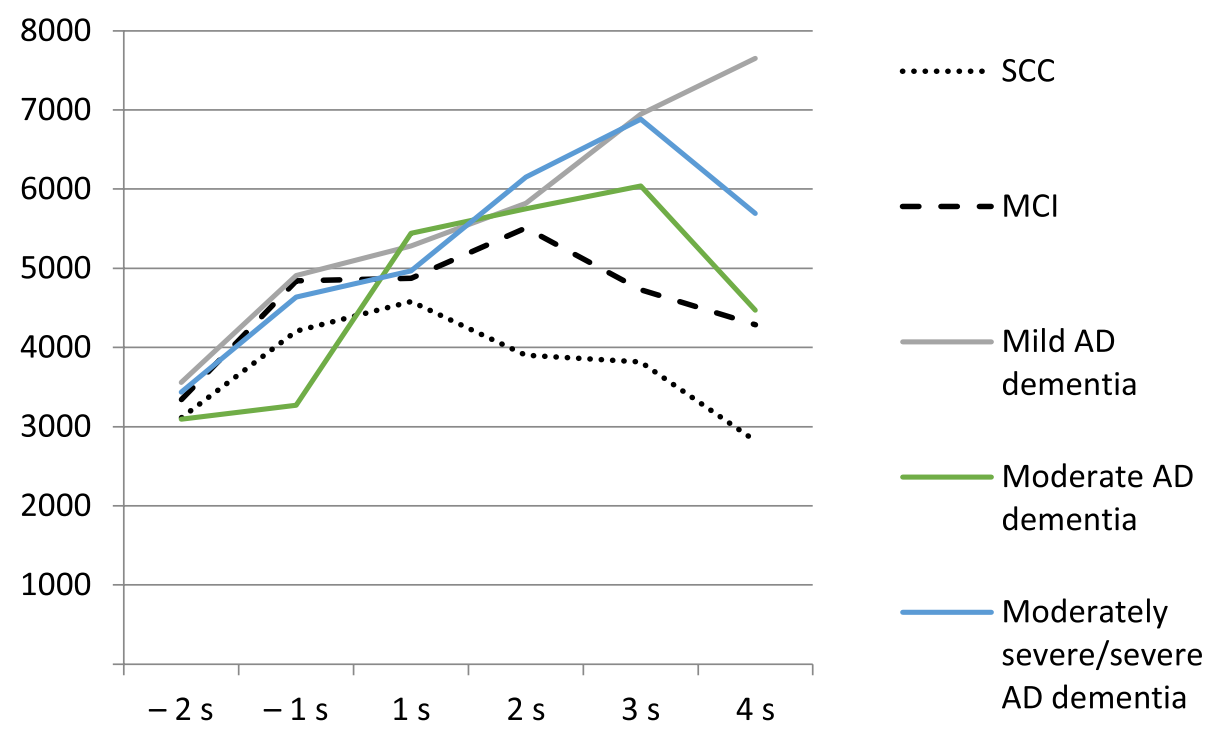

Fig. 1 Total costs in euros per semester across the disease stages. AD, Alzheimer's disease; MCl, mild cognitive impairment; SCC, subjective cognitive complaint. $-2 \mathrm{~s}$ : second semester before the memory visit; $4 \mathrm{~s}$ : fourth semester after the memory visit

Examining cost details revealed that most of the total direct medical costs were explained by public hospital stays, followed by paramedical care, for all groups (Supplementary Table 3). Public hospital stays represented an average of $49.4 \%$ of the total costs during the first semester after the first visit, and paramedical care represented an average of $20.4 \%$ of the total costs. The total ambulatory costs were lower, whereas the total paramedical costs were higher in AD dementia groups compared with SCC and MCI groups. General practitioner visits represented an average of $10.1 \%$ of the total ambulatory costs for the first semester after the first visit. The costs associated with paramedical care were mostly due to care by nurse $(76 \%$ of the total paramedical costs for the first semester after the first visit). AD medication costs increased with diagnosis severity but represented a modest proportion $(10.6 \%$ for the first semester after the first visit) of the costs associated with pharmaceutical treatment compared with all other medications combined. Stays in public geriatric and psychiatric wards accounted for $35.6 \%$ of the total costs of stays in public hospitals. Costs are described in more detail in Supplementary Table 4.

\section{Costs according to patient demographics}

Total costs by age, sex, education level, and treatment for comorbidities are presented in Supplementary Table 5. Mean total costs were higher for patients $>80$ years and for patients with less education. Mean total costs were higher for men than women the year before diagnosis and the first semester after. Total costs were numerically higher for patients treated for comorbidities of interest.

\section{Caregiver burden according to the severity of cognitive deficit}

The association between caregiver burden and disease severity was assessed in 1367 patients. Caregiver burden increased with disease severity independent of age and sex (mean sZBI scores: $\mathrm{SCC}=2.2 \pm 1.9$; $\mathrm{MCI}=2.4 \pm$ 1.8; mild AD dementia $=3.1 \pm 1.8$; moderate AD dementia $=3.4 \pm 1.8$; moderately severe/severe $\mathrm{AD}$ dementia $=$ $3.8 \pm 1.8 ; P<.001$ ) (Fig. 2).

\section{Sensitivity analysis}

When outlier patients with costs $\geq 3$ SDs above-average total costs were excluded, mean values better reflected the median. In the first year after the initial visit, the SCC group had a mean total cost of $€ 5989$, with a median cost of $€ 1709$ (Table 3). Furthermore, in the mild AD dementia group, the mean cost was $€ 7336$, and the median was $€ 4670$. The trend for costs to increase with disease severity (in patients with SCC, MCI, or AD dementia) was preserved in the sensitivity analysis (Table 3 ; Supplementary Table 6). In the AD dementia groups, the average total costs were numerically higher in the moderately severe/ severe AD dementia group (€7834) compared with the mild (€7336) and moderate AD (€7315) groups. The evolution of the average total costs over time remained similar in the sensitivity analysis, except in the moderate $\mathrm{AD}$ dementia group, for which the average total costs 


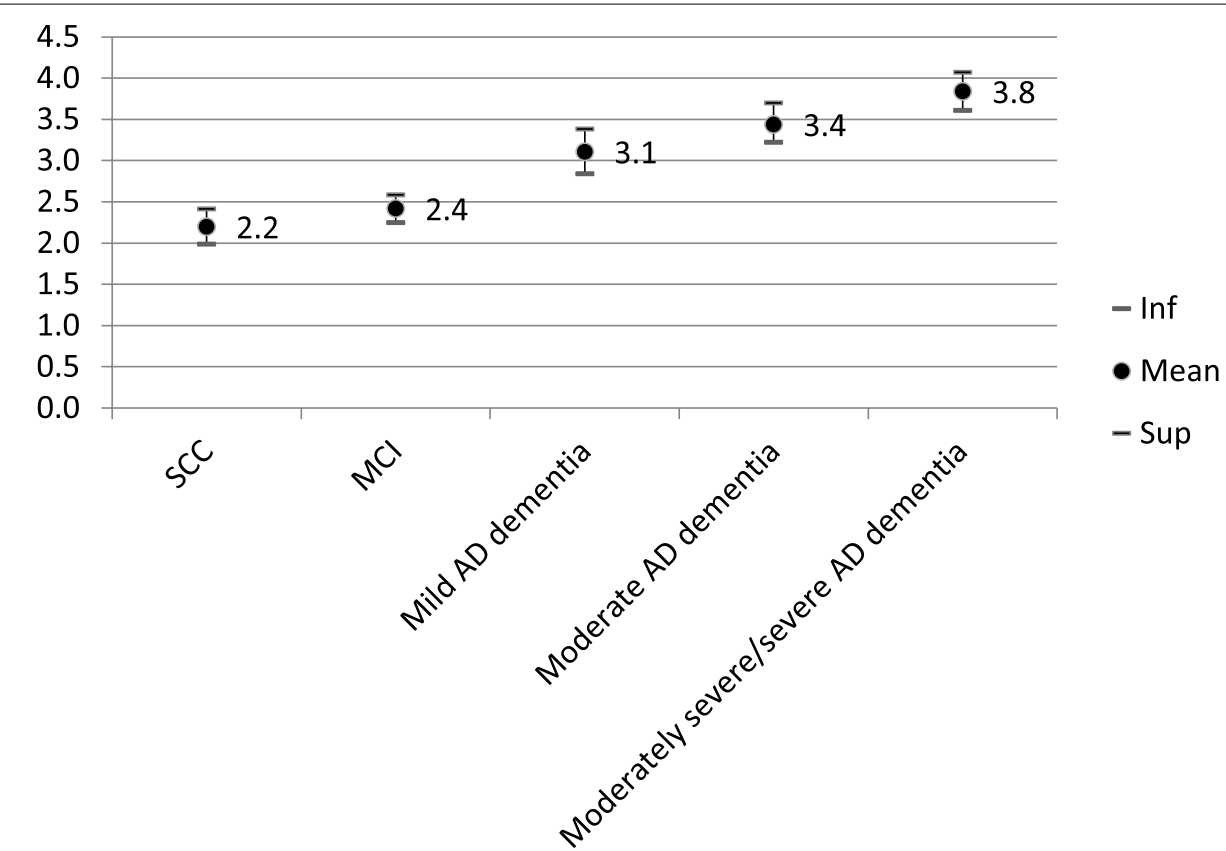

Fig. 2 Caregiver burden across the disease stages. * sZBI scores range from 0 to 7, with a higher number corresponding to increased caregiver burden. AD, Alzheimer's disease; MCl, mild cognitive impairment; Inf, limit inferior of the $95 \%$ confidence interval, SCC, subjective cognitive complaint; Sup, limit superior of the $95 \%$ confidence interval. $(N=1367 ; P<.0001)$

increased both years after the initial visit, similar to the mild and moderately severe/severe AD dementia groups.

When comparing the patient characteristics of outliers $(n=51)$ with the rest of the population $(n=1947)$ in the first semester, outliers were more frequently treated for anxiety $(49 \%$ vs. $32.1 \% ; P=.011)$ and diabetes mellitus (31.4\% vs. $17.7 \% ; P=.012$ ) (Supplementary Table 7), and the IADL score was lower in the outlier group than in the rest of the population (IADL, 3.8 vs. $5.1 ; P<.0001$ ).

\section{Discussion}

In this study, we describe direct medical costs and medical transportation costs according to the severity of cognitive impairment. Direct medical and nonmedical (ie, medical transportation) costs and caregiver burden significantly increased with greater progression of cognitive deficit in the SCC, MCI, and AD dementia groups. Costs increased with disease severity when assessed both before and after the initial visit. These results build on previous findings suggesting that greater cognitive impairment results in higher direct medical costs and higher caregiver impact in various settings $[7,9,21,22$, 24-33].

Although there was a trend of increased cost with greater cognitive decline, medical costs were similar the first year after diagnosis among the different cognitive stages in $\mathrm{AD}$ dementia. This finding is consistent with those of previous studies that did not highlight significant differences among the severity stages in AD dementia [5, $6,34,35$ ] (Supplementary Table 8), while others studies have shown that the healthcare costs increased among different cognitive stages of AD dementia [21, 27, 36, 37]. In our study, similar costs between the different cognitive stages in $A D$ dementia may be explained by the fact that patients with higher healthcare costs are less represented in the more severe stages of AD dementia due to nursing home admission or death. In our study, the proportions of nursing home admissions and deaths were higher in the moderately severe/severe stage of AD dementia than in the less severe stages (Supplementary Table 9), and the costs related to nursing homes are not covered by the PHIF. In a post hoc analysis, where the patients who were admitted to a nursing home or died were excluded, the average direct medical cost was $€ 7178$ in the mild AD group, $€ 7164$ in the moderate AD group, and $€ 8264$ in the moderately severe/severe $\mathrm{AD}$ group.

Another possible explanation is that the costs may shift from the medical sector covered by the PHIF to other social care sectors. While this study presented the direct medical costs covered by the local PHIF, previous studies have shown increased patient social care and caregiver informal care costs with the cognitive severity groups in $\mathrm{AD}$ dementia, while the patient healthcare costs were similar or decreased between the groups $[5,6,34]$. 
Table 3 Mean total cost/year after exclusion of costs $\geq 3$ SD of the average total costs

\begin{tabular}{|c|c|c|c|c|}
\hline Costs, $€$ & & 1 year before & 1 year after & 2 years after \\
\hline \multirow[t]{5}{*}{ SCC } & Mean & 4460 & 5989 & 4749 \\
\hline & SE & 314 & 353 & 332 \\
\hline & Median & 1709 & 2451 & 1761 \\
\hline & SD & 7637 & 8803 & 7424 \\
\hline & IQR & 1991 & 3017 & 2754 \\
\hline \multirow[t]{5}{*}{$\mathrm{MCl}$} & Mean & 5514 & 7272 & 6629 \\
\hline & SE & 354 & 394 & 400 \\
\hline & Median & 1979 & 3339 & 3074 \\
\hline & SD & 8580 & 9728 & 8913 \\
\hline & $I Q R$ & 2354 & 4277 & 4050 \\
\hline \multirow{5}{*}{$\begin{array}{l}\text { Mild AD demen- } \\
\text { tia }\end{array}$} & Mean & 6021 & 7336 & 7771 \\
\hline & SE & 623 & 563 & 761 \\
\hline & Median & 2323 & 4670 & 4796 \\
\hline & SD & 8815 & 8045 & 9591 \\
\hline & IQR & 2826 & 4542 & 4190 \\
\hline \multirow{5}{*}{$\begin{array}{l}\text { Moderate AD } \\
\text { dementia }\end{array}$} & Mean & 5320 & 7315 & 7741 \\
\hline & SE & 499 & 561 & 681 \\
\hline & Median & 1994 & 4085 & 3983 \\
\hline & SD & 7715 & 8776 & 9631 \\
\hline & IQR & 3464 & 5152 & 5790 \\
\hline \multirow{5}{*}{$\begin{array}{l}\text { Moderately } \\
\text { severe/severe AD } \\
\text { dementia }\end{array}$} & Mean & 6148 & 7834 & 8303 \\
\hline & SE & 529 & 638 & 724 \\
\hline & Median & 2160 & 3909 & 4453 \\
\hline & SD & 8316 & 10141 & 9880 \\
\hline & IQR & 3891 & 5907 & 7425 \\
\hline$P$ value* & & 0.002 & 0.006 & $<0.0001$ \\
\hline$P$ value $^{\dagger}$ & & 0.065 & 0.409 & $<0.0001$ \\
\hline
\end{tabular}

$A D$ Alzheimer's disease, GLM generalized linear model, IQR interquartile range, $\mathrm{MCl}$ mild cognitive impairment, SCC subjective cognitive complaint, SD standard deviation, SE standard error

*GLM to compare mean total costs between the different diagnoses

${ }^{\dagger}$ GLM adjusted for age, sex, and education level

Finally, when outlier patients with costs $\geq 3$ SDs aboveaverage total costs were removed from the sensitivity analysis, we found that medical costs were numerically higher in the more severe AD dementia group, which may mean that extreme costs are related to medical conditions other than cognitive decline.

Higher healthcare costs were observed in this study compared with those in the French GERAS cohort, which analyzed data from patients at memory clinics with mild, moderate, or moderately severe/severe $\mathrm{AD}$ dementia. These higher costs in the MEMORA cohort were observed even after accounting for differences in the years that the costs were reported [37]. In the GERAS study, healthcare costs over 18 months were $€ 5129$ for mild AD dementia, €7106 for moderate AD dementia, and $€ 8118$ for moderately severe/severe AD dementia [37]. In contrast, costs 1 year after the first visit to a memory clinic reported in our study were $€ 10,558 €$ for mild AD dementia (€7336 in the sensitivity analysis), $€ 10,544$ for moderate AD dementia ( $€ 7315$ in the sensitivity analysis), and $€ 10,345$ for moderately severe/severe AD dementia ( $€ 7834$ in the sensitivity analysis). The MMSE was used to define the severity of AD dementia in both studies, and the mean age and mean MMSE scores at baseline were comparable for each level of disease severity, suggesting that these factors did not impact differences in costs. Given this, it is likely that the cost differences between the present study and GERAS cohorts differed because GERAS captured healthcare resources using the Resource Utilization in Dementia instrument, which is patient and caregiver reported, rather than analyzing data extracted from the PHIF claims database. Also, the present study included all direct medical costs of patients visiting a memory clinic, even those related to medical conditions other than $\mathrm{AD}$ dementia.

In our study, the majority of direct medical costs were incurred during public hospital stays, which is consistent across studies in Europe and the US [10,21].

Regardless of the disease stage, costs increased the year after the first consultation. Two years after the first consultation, the evolution of costs varied according to the patient group: The average total cost decreased in patients with SCC and MCI and increased in the AD dementia groups. An explanation for this result may be that another medical condition caused the patient to enter into the healthcare system initially; thus, the bulk of the costs in the first year could be associated with another medical condition unrelated to cognitive impairment. Alternatively, cognitive decline may have been the rationale to seek a memory clinic consultation, which may have led to increased care services to confirm a diagnosis and to create an individualized care or management plan [38].

Total costs were higher for older patients and patients treated for comorbidities (i.e., arterial hypertension, diabetes mellitus, hypercholesterolemia, depression, and anxiety), which is consistent with previous studies [39]. Additionally, the observed increase in disease burden with $\mathrm{AD}$ progression, from mild to moderately severe/severe AD dementia, is also consistent with the previous literature [40]. Importantly, this study extends previous work by addressing the burden of disease at earlier stages of cognitive decline (e.g., SCC and MCI). Results showed that the burden of disease is comparable across these early disease stages.

As typical in costs analyses, there were some patients who accumulated particularly high costs, resulting in discrepancies between means and medians. Skewed 
data was accounted for using gamma function in the models, and a sensitivity analysis was performed with statistically significant, high-costs outliers removed from the sample. Results of the sensitivity analysis showed that patients with extremely high costs were generally in poorer health and had a higher incidence of anxiety, which is consistent with previous studies $[41,42]$. As such, these factors help explain the elevated costs associated with these patients.

In this study, direct medical and nondirect transportation costs were assessed using information from the PHIF claims database. To our knowledge, this is the first study to describe direct medical costs and medical transportation costs according to the severity of cognitive impairment in France from the perspective of the public payer and to report the costs before and after an initial memory clinic visit. Approximately $90 \%$ of the French population is covered by the PHIF; therefore, using this database permitted a reliable representation of the health spending from the public payer [13].

\section{Limitations}

Besides transportation, other nonmedical direct costs, such as home support and indirect costs, were not included in cost analyses because these costs are not covered by the PHIF. As such, nonmedical costs, like informal care time, which may represent $50 \%$ to $80 \%$ of the overall costs associated with AD depending on the study $[35,37]$, should be taken into consideration in future studies evaluating the total economic cost of AD. Moreover, all costs covered by the PHIF were considered in this study, including those that are not specifically related to $\mathrm{AD}$. This may have led to an overestimation of the direct medical costs; nevertheless, this overestimation may be present for all groups compared in this study. Also of note, the healthcare coverage of the PHIF is specific to the French national system. National health policies differ between countries and can change over time; in France, for example, reimbursement for drugs used to treat AD (donepezil, galantamine, memantine, and rivastigmine) ended in 2018. The health care that is not reimbursed by the PHIF may be reimbursed by private insurance or paid by the patients or their families.

The neurocognitive diagnosis was determined at the first visit; thus, it is important to consider that the evolution of costs over time may have been accompanied by the decline of patients' health statuses, particularly cognitive and functional impairment in the $\mathrm{AD}$ dementia groups. It is less certain for patients in the SCC and the MCI groups, whose disease may not progress to a more advanced stage. Although the data did not allow us to show patients' health status decline, the increase in nursing home admissions and deaths over time supports this hypothesis (Supplementary Table 9).

AD was diagnosed based on clinical and neuropsychological evaluations and was not confirmed by biomarkers. Future studies should include biomarker assessment during diagnosis. The present study is limited to findings from an older French population at 1 memory clinic; however, the patients' characteristics were comparable to those of the multicentric GERAS cohort in France [37]. Nevertheless, it will be important to conduct cost analyses across other geographical and social policy contexts.

\section{Conclusions}

The economic toll of $\mathrm{AD}$ is debilitating and continues to grow. These results show that direct medical costs and caregiver burden rise with the severity of cognitive impairment from SCC to AD dementia; they were similar in the $\mathrm{AD}$ dementia groups that were determined by the MMSE. In AD dementia, the direct medical costs increased 2 years after the first consultation in a memory clinic. These results, in conjunction with data from other care components, will be critical in revealing the potential economic value of a therapeutic intervention that halts or slows the progression of AD.

\section{Abbreviations}

AD: Alzheimer's disease; CPAM: Caisse Primaire d'Assurance Maladie du Rhône; GLM: Generalized linear models; IADL: Lawton Instrumental Abilities of Daily

Living; IQR: Interquartile range; MCI: Mild cognitive impairment; MMSE: Mini-Mental State Examination; NPI: Neuropsychiatric Inventory; PHIF: Primary Health Insurance Fund; SCC: Subjective cognitive complaint; SD: Standard deviation; SE: Standard error; SPSS: Statistical Package for the Social Sciences; sZBI: Short version of the Zarit Burden Interview.

\section{Supplementary Information}

The online version contains supplementary material available at https://doi. org/10.1186/s13195-022-00969-x.

\author{
Additional file 1: Table S1. \\ Additional file 2: Figure S1. Flowchart. \\ Additional file 3: Table S2. Cost by Semester. \\ Additional file 4: Table S3. Cost by Domain 1. \\ Additional file 5: Table S4. Cost by Domain 2. \\ Additional file 6: Table S5. Cost by Characteristics. \\ Additional file 7: Table S6. Sensitivity. \\ Additional file 8: Table S7. Characteristics of patients.
}

Additional file 9: Table S8. Other Studies.

Additional file 10: Table S9. Events.

\section{Acknowledgments}

We thank Pascale Gauthier-Robino and Laurent Colas from the Primary Health Insurance Fund of the Rhône (CPAM Rhône), Lyon, France, for their help in the collection of claims data. We also thank Claire Moutet and Floriane Delphin-Combe for their help with data management. We are grateful to 
the participants and the hospital staff. Medical writing support, under the direction of the authors, was provided by MediTech Media and was funded by Biogen.

\section{Authors' contributions}

All authors have contributed substantially to this work and meet criteria for authorship as stated in the Uniform Requirements for Manuscripts Submitted to Biomedical Journals, and each author's contribution is listed below: Study concept and design: Virginie Dauphinot (VD), Michele Potashman (MP), Mihaela Levitchi-Benea (MLB), Ray Su (RS), Ivana Rubino (IR), Pierre Krolak-Salmon (PKS). Acquisition of data: VD, PKS. Analysis and interpretation of data: VD, MP, MLB, RS, IR, PKS. Drafting of the manuscript: VD, MP. Critical revision of the manuscript for important intellectual content: VD, MP, MLB, RS, IR, PKS. All authors have read and approved this final version of the manuscript.

\section{Funding}

The MEMORA study and its ancillary study have received funding support from Biogen and the MSD Avenir Fund. The Biogen and MSD Avenir Fund support enabled the funding of nurses to carry out the research and questionnaires. This MSD Avenir fund has no role in the design of the study, the collection, the analysis, the interpretation, or the writing of the present manuscript. Biogen had a role in the design of the present study, the analysis and interpretation of the data, and the writing of the present manuscript.

\section{Availability of data and materials}

The data sets analyzed in the present study are not publicly available due to regulations; the ethics board and the French Data Protection Authority, as well as the patients, were informed that their data would be analyzed only by the French Lyon University Hospital, and agreements obtained to perform the study (the contract between the local branch of the PHIF and the Lyon University Hospital) state that the claims data will not be transmitted outside the Lyon University Hospital. Collaborations to further explore these data are welcomed on request to the corresponding or last author. The data of the MEMORA study and this ancillary study are the property of the French Lyon University Hospital, France.

\section{Declarations}

\section{Ethics approval and consent to participate}

Information regarding the collection of individual data, with the aim of performing research on routine care, was provided to the patients. This research is an ancillary study of the MEMORA cohort. This ancillary study, conducted in routine care, was considered noninterventional by the local ethics committee CPP Lyon Sud-Est IV (Comité de Protection des Personnes [Committee for the Protection of People]). No signed consent to participate was required, but patients may refuse the use of their data for research purpose. Authorization for handling personal data was granted by the representative of the French Data Protection Authority, CNIL: Commission Nationale de I'Informatique et Libertés. All procedures are in compliance with the Declaration of Helsinki. The MEMORA cohort also obtained agreements from the regional ethics committee (Comité de Protection des Personnes Sud Est III) and the French Data Protection Authority (NCT02302482).

\section{Consent for publication}

Not applicable.

\section{Competing interests}

Mihaela Levitchi-Benea and Ivana Rubino are employees of Biogen, Cambridge, MA, USA. Michele Potashman and Ray Su were employees of Biogen at the time this work was conducted. Virginie Dauphinot and Pierre Krolak-Salmon are employees of the Lyon University Hospital and University of Lyon, France.

\section{Author details}

${ }^{1}$ Clinical and Research Memory Centre of Lyon, Lyon Institute For Elderly, Lyon University Hospital, Lyon, France. ${ }^{2}$ University of Lyon, Lyon, France. ${ }^{3}$ Biogen, Cambridge, MA, USA. ${ }^{4}$ Neuroscience Research Centre of Lyon, Inserm 1048, CNRS, 5292 Lyon, France.
Received: 26 April 2021 Accepted: 30 January 2022

Published online: 12 February 2022

\section{References}

1. Wimo A, Jonsson L, Bond J, Prince M, Winblad B. The worldwide economic impact of dementia 2010. Alzheimers Dement. 2013;9:1-11.

2. Olesen J, Gustavsson A, Svensson M, Wittchen HU, Jönsson B. The economic cost of brain disorders in Europe. Eur J Neurol. 2012;19:155-62.

3. Jack CR Jr, Bennett D, Blennow K, Carrillo MC, Feldman HH, Frisoni GB, et al. A/T/N: an unbiased descriptive classification scheme for Alzheimer disease biomarkers. Neurology. 2016;87:539-47.

4. Reed C, Happich M, Argimon JM, Haro JM, Wimo A, Bruno G, et al. What drives country differences in cost of Alzheimer's disease? An explanation from resource use in the GERAS study. J Alzheimer Dis. 2017;57:797-812.

5. Olazarán J, Aguera-Ortiz L, Argimon JM, Reed C, Ciudad A, Andrade P, et al. Costs and quality of life in community-dwelling patients with Alzheimer's disease in Spain: results from the GERAS II observational study. Int Psychogeriatr. 2017;29:2081-93.

6. Lenox-Smith A, Reed C, Lebrec J, Belger M, Jones RW. Resource utilisation, costs and clinical outcomes in non-institutionalised patients with Alzheimer's disease: 18-month UK results from the GERAS observational study. BMC Geriatr. 2016;16:195.

7. Schaller S, Mauskopf J, Kriza C, Wahlster P, Kolominsky-Rabas PL. The main cost drivers in dementia: a systematic review. Int J Geriatr Psychiatry. 2015;30:111-29.

8. Sicras A, Rejas J, Arco S, Flores E, Ortega G, Esparcia A, et al. Prevalence, resource utilization and costs of vascular dementia compared to Alzheimer's dementia in a population setting. Dement Geriatr Cogn Disord. 2005;19:305-15.

9. Murman DL, Von Eye A, Sherwood PR, Liand J, Colenda CC. Evaluated need, costs of care, and payer perspective in degenerative dementia patients cared for in the United States. Alzheimer Dis Assoc Disord. 2007;21:39-48.

10. Leibson C, Long KH, Ransom JE, Roberts RO, Hass SL, Duhig AM, et al. Direct medical costs and source of cost differences across the spectrum of cognitive decline: a population-based study. Alzheimers Dement. 2015;11:917-32.

11. Dauphinot V, Moutet C, Rouch I, Verdurand M, Mouchoux C, DelphinCombe F, et al. A multicenter cohort study to investigate the factors associated with functional autonomy change in patients with cognitive complaint or neurocognitive disorders: the MEMORA study protocol. BMC Geriatr. 2019;19:191.

12. Dauphinot V, Garnier-crussard A, Moutet C, Delphin-Combe F, Späth HM, Krolak-Salmon P. Determinants of medical direct costs of care among patients of a memory center. J Prev Alzheimers Dis. 2021;8:351-61.

13. Tuppin $P$, de Roquefeuil $L$, Weill $A$, Ricordeau $P$, Merlière $Y$. French national health insurance information system and the permanent beneficiaries sample. Rev Epidemiol Sante Publique. 2010;58:286-90.

14. Zarit SH, Todd PA, Zarit JM. Subjective burden of husbands and wives as caregivers: a longitudinal study. Gerontologist. 1986;26:260-6.

15. Folstein M, Folstein S. Mini-mental state: a practical method for grading the cognitive stade of patients for the clinician. J Psychiatr Res. 1975;12:189-98.

16. Lawton M, Brody E. Assessment of older people: self-maintaining and instrumental activities of daily living. Gerontologist. 1969;9:179-86.

17. Cummings JL, Mega M, Geay K, Rosenberg-Thompson S, Carusi DA, Gornbein J. The Neuropsychiatric Inventory: comprehensive assessment of psychopathology in dementia. Neurology. 1994;44:2308-14.

18. Albert MS, DeKosky ST, Dickson D, Dubois B, Feldman HH, Fox NC, et al. The diagnosis of mild cognitive impairment due to Alzheimer's disease: recommendations from the National Institude on Aging-Alzheimer's Association workgroups on diagnosis guidelines for Alzheimer's disease. Alzheimers Dement. 2011;7:270-9.

19. McKhann G, Knopman D, Chertkow H, Hyman B, Cj J, Kawas C, et al. The diagnosis of dementia due to Alzheimer's disease: recommendations from the National Institute on Aging-Alzheimer's Association worgroups on diagnosis guidelines for Alzheimer's disease. Alzheimers Dement. 2011;7:263-9. 
20. American Psychiatric Association, editor. Diagnostic and statistical manual of mental disorders. 5th ed. Washington, DC: American Psychiatric Association; 2013.

21. Wimo A, Reed C, Dodel R, Belger M, Jones RW, Happich M, et al. The GERAS Study: a prospective observational study of costs and resource use in community dwellers with Alzheimer's disease in three European countries - study design and baseline findings. J Alzheimers Dis. 2013;36:385-99.

22. Dodel R, Belger M, Reed C, Wimo A, Jones RW, Happich M, et al. Determinants of societal costs in Alzheimer's disease: GERAS study baseline results. Alzheimers Dement. 2015;11:933-45.

23. Diehr P, Yanez D, Ash A, Hornbrook M, Lin D. Methods for analyzing health care utilization and costs. Annu Rev Public Health. 1999;20:125-44.

24. Zhu CW, Leibman C, McLaughlin T, Scarmeas N, Albert M, Brandt J. The effects of patient function and dependence on costs of care in Alzheimer's disease. J Am Geriatr Soc. 2008;56:1497-503.

25. Jönsson L, Eriksdotter Jönhagen M, Kilander L, Soininen H, Hallikainen M, Waldemar G, et al. Determinants of costs of care for patients with Alzheimer's disease. Int J Geriatr Psychiatry. 2006;21:449-59.

26. Darbà J, Kaskens L, Lacey L. Relationship between global severity of patients with Alzheimer's disease and costs of care in Spain; results from the co-dependence study in Spain. Eur J Health Econ. 2015;16:895-905.

27. Rigaud AS, Fagnani F, Bayle C, Latour F, Traykov L, Forette F. Patients with Alzheimer's disease living at home in France: costs and consequences of the disease. J Geriatr Psychiatry Neurol. 2003;16:140-5.

28. Mauskopf J, Racketa J, Sherrill E. Alzheimer's disease: the strength of association of costs with different measures of disease severity. J Nutr Health Aging. 2010;14:655-63.

29. Gustavsson A, Brinck P, Bergvall N, Kolasa K, Wimo A, Winblad B, et al. Predictors of costs of care in Alzheimer's disease: a multinational sample of 1222 patients. Alzheimers Dement. 2011;7:318-27.

30. Mesterton J, Wimo A, By A, Langworth S, Winblad B, Jönsson L. Crosssectional observational study on the societal costs in Alzheimer's disease. Curr Alzheimer Res. 2010;7:358-67.

31. Handels RL, Wolf CA, Aalten P, Verhey FR, Severens JL. Determinants of care costs of patients with dementia or cognitive impairment. Alzheimer Dis Assoc Disord. 2013;27:30-6.

32. Jones RW, Lebrec J, Kahle-Wrobleski K, Dell'Agnello G, Bruno G, Vellas B, et al. Disease progression in mild dementia due to Alzheimer disease in an 18-month observational study (GERAS): the impact on costs and caregiver outcomes. Dement Geriatr Cogn Dis Extra. 2017;7:87-100.

33. Luppa M, Heinrich S, Matschinger H, Hensel A, Luck T, Riedel-Heller SG, et al. Direct costs associated with mild cognitive impairment in primary care. Int J Geriatr Psychiatry. 2008;23:963-71.

34. Bruno G, Mancini M, Bruti G, Dell'Agnello G, Reed C. Costs and resource use associated with Alzheimer's disease in Italy: results from an observational study. J Prev Alzheimers Dis. 2018;5:56-64.

35. Rapp T, Andrieu S, Molinier L, Grand A, Cantet C, Mullins D, et al. Exploring the relationship between Alzheimer's disease severity and longitudinal costs. Value Health. 2012;15:412-9.

36. Gervès C, Chauvin P, Bellanger M. Evaluation of full costs of care for patients with Alzheimer's disease in France: the predominant role of informal care. Health Policy. 2014;116:114-22.

37. Rapp T, Andrieu S, Chartier F, Deberdt W, Reed C, Belger M, et al. Resource use and cost of Alzheimer's disease in France: 18-month results from the GERAS observational study. Value Health. 2018;21:295-303.

38. Wardorff FB, Siersma V, Waldemar G. Association between subjective memory complaints and health care utilisation: a three-year follow up. BMC Geriatr. 2009;9:43.

39. Zhu CW, Cosentino S, Orsntein KA, Gu Y, Andrews H, Stern Y. Interactive effects of dementia severity and comorbidities on medicare expenditures. J Alzheimers Dis. 2017;57:305-15.

40. Aguëra-Ortiz L, Frank-Garcia A, Gil P, Moreno A. Clinical progression of moderate-to-severe Alzheimer's disease and caregiver burden: a 12-month multicenter prospective observational study. Int Psychogeriatr. 2010;22:1265-79.

41. Konnopka A, König H. Economic burden of anxiety disorders: a systematic review and meta-analysis. Pharmacoeconomics. 2020;38:25-37.

42. Cortaredona S, Ventelou B. The extra cost of comorbidity: multiple illnesses and the economic burden of non-communicable diseases. BMC Med. 2017;15:216.

\section{Publisher's Note}

Springer Nature remains neutral with regard to jurisdictional claims in published maps and institutional affiliations.
Ready to submit your research? Choose BMC and benefit from:

- fast, convenient online submission

- thorough peer review by experienced researchers in your field

- rapid publication on acceptance

- support for research data, including large and complex data types

- gold Open Access which fosters wider collaboration and increased citations

- maximum visibility for your research: over $100 \mathrm{M}$ website views per year

At BMC, research is always in progress.

Learn more biomedcentral.com/submissions 